\title{
BMJ Open How did the tobacco ban increase inmates' body weight during incarceration in Canadian federal penitentiaries? A cohort study
}

\author{
Claire Johnson, ${ }^{1}$ Jean-Philippe Chaput, ${ }^{2}$ Maikol Diasparra, ${ }^{3}$ Catherine Richard, ${ }^{4}$ \\ Lise Dubois ${ }^{4}$
}

To cite: Johnson C, Chaput J-P, Diasparra M, et al. How did the tobacco ban increase inmates' body weight during incarceration in Canadian federal penitentiaries? A cohort study. BMJ Open 2019;9:e024552. doi:10.1136/ bmjopen-2018-024552

\section{- Prepublication history for} this paper is available online. To view these files, please visit the journal online (http://dx.doi. org/10.1136/bmjopen-2018024552).

Received 6 June 2018 Revised 23 May 2019 Accepted 28 June 2019

A) Check for updates

(c) Author(s) (or their employer(s)) 2019. Re-use permitted under CC BY-NC. No commercial re-use. See rights and permissions. Published by BMJ.

${ }^{1}$ Interdisciplinary School of Health Sciences, University of Ottawa, Ottawa, Ontario, Canada ${ }^{2}$ Department of Human Nutrition, Children's Hospital of Eastern Ontario Research Institute, Ottawa, Ontario, Canada ${ }^{3}$ School of Epidemiology and Public Health, University of Ottawa Faculty of Medicine, Ottawa, Ontario, Canada

${ }^{4}$ School of Epidemiology and Public Health, University of Ottawa, Ottawa, Ontario, Canada

Correspondence to

Claire Johnson;

cjohn127@uottawa.ca

\section{ABSTRACT}

Objective This study aimed to determine how inmates' body weight changed during incarceration in Canadian federal penitentiaries, based on their history of tobacco use. Since tobacco was banned from all Canadian federal penitentiaries in 2008, little is known about the unintended health consequences of this ban, especially on inmates' body weight.

Design Cohort study.

Setting Participants were male and female inmates incarcerated for at least 6 months in Canadian federal penitentiaries. We collected data from 10 institutions in two Canadian regions (Ontario and Atlantic).

Participants We collected data from 754 inmates who volunteered to participate in the study.

Intervention This study examined weight change in relation to a history of tobacco use. In 2016-2017, anthropometric data were collected and compared with recorded anthropometric data at the beginning of incarceration (mean follow-up of $5.0 \pm 8.3$ years). Self-reported data on tobacco and substance use were collected. Weight change was compared between inmates with and without a history of tobacco use.

Outcomes The main outcome measures were body weight change $(\mathrm{kg})$, body mass index (BMI) change $(\mathrm{kg} /$ $\mathrm{m}^{2}$ ), annual weight change ( $\left.\mathrm{kg} / \mathrm{year}\right)$, and BMI and waist circumference $(\mathrm{cm})$ at the time of the interview.

Results During incarceration, ex-smokers gained more than twice the amount of weight compared with nonsmokers $(7.5 \mathrm{~kg}$ weight gain for smokers vs $3.7 \mathrm{~kg}$ weight gain for non-smokers). Once adjusted for covariates in a regression analysis, for inmates who gained the most weight (75th and 90th percentiles), non-smokers had, respectively, 1.64 and 2.3 lower BMI points than ex-smokers. Conclusions During incarceration in Canadian federal penitentiaries, inmates with a history of tobacco use gained significantly more weight than non-smokers. This put them at increased risk of developing obesity-related health problems. This information is important for the prison setting when planning related programmes and regulation.

\section{INTRODUCTION}

Smoking, whether permitted or not, is a major part of the prison culture, mainly because so
Strengths and limitations of this study

A strength of this study is its large sample size.

- Another strength is the prison setting, where it is possible to assess objectively measured weight change (outcome measurement) from admission to follow-up in a closed controlled environment.

- A limitation is that the data related to tobacco use were self-reported and therefore subject to recall and social desirability biases.

- The recruitment process was voluntary, and therefore there is a risk for selection bias.

- Another limitation is the observational nature of the data, which precludes inferences about causality, and residual confounding by unmeasured variables is possible.

many inmates identify as smokers. In Canada, smoking rates among inmates, prior to incarceration, are estimated to be between $50 \%$ and $93 \%{ }^{1-7}$ Those rates are four to five times the smoking rate of the general Canadian population, ${ }^{5}$ estimated to be between $13 \%$ and $17 \% .^{8-10}$ The primary reason why smoking rates are so high among prisoners is because many of them suffer from conditions that correlate with high tobacco use, including substance misuse, psychiatric disorders, poor impulse control and low socioeconomic backgrounds. ${ }^{1112}$ Traditionally, before the tobacco ban in Canadian federal penitentiaries, the high rates of smoking meant inmates and staff were exposed to unusually high amounts of secondhand smoke. ${ }^{13}$ We know from studies on tobacco control in prison that total tobacco bans have reached their goal of reducing harmful exposure to secondhand smoke and subsequently reducing related ailments. ${ }^{14}$ In 2008, Canada proactively took the lead and adopted a total tobacco ban for all 41 federal correctional institutions. ${ }^{15}$ This means of the 14000 inmates incarcerated 
in federal penitentiaries across Canada, approximately 10000 were forced to quit smoking on admission to the penitentiary (or quit smoking when the ban occurred in 2008).$^{16}$ Although the tobacco ban is considered a good public health measure in several aspects (eg, improving air quality), there is a lack of research on the unintended consequences of tobacco bans in prisons. ${ }^{17-19}$ It is relevant to examine these unintended consequences because many prisons are now implementing tobacco control policies (from partial indoor bans to completely prohibiting tobacco) worldwide. $^{720-22}$ Our findings on weight gain as an unintended consequence of a total tobacco ban could influence decision makers on their choice of tobacco control regulation and the support provided to inmates withdrawing from tobacco during incarceration.

Generally, studies on obesity in prison found obesity prevalence in male inmates to be similar or lower than the general population. ${ }^{23-25}$ However, many of the studies were self-reported, cross-sectional and did not assess change in weight during incarceration. Of the studies that did assess weight gain in prison, findings revealed that $50 \%-80 \%$ of inmates gained weight during incarceration. ${ }^{26}$ Moreover, there appears to be important variability in weight gain, ranging from a modest $0.96 \mathrm{~kg}$ over 2 years $^{27}$ to a substantial $0.5 \mathrm{~kg}$ gain per week. ${ }^{28}$ When inmates gained substantial amounts of weight, authors often speculated it is because of withdrawal from tobacco, alcohol or drugs. ${ }^{28}{ }^{29}$ However, they lack data to back up these claims, since there are few data on the factors that contribute to weight gain during incarceration. ${ }^{24} \mathrm{An}$ American study demonstrated that female prisoners who participated in a voluntary smoking cessation programme (that included transdermal nicotine replacement) while incarcerated gained more weight at the 6-month postcessation follow-up compared with inmates who continued to smoke (on average $4.5 \mathrm{~kg}$ more than smokers). ${ }^{30}$

The majority of studies on obesity in prison were out of Australia, the USA and the UK. ${ }^{26}$ In our recent publication, we found that Canadian inmates gained a significant amount of weight during incarceration. ${ }^{25}$ Our findings showed that, on admission, obesity rates were similar to the general Canadian population $(\sim 27 \%)$, but after at least 6 months of incarceration obesity rates increased to $45 \%$ for the inmate population. ${ }^{25}$ We suspect the observed weight gain was associated with tobacco cessation in Canadian inmates.

To fill this knowledge gap, this study examined, for the first time, how inmates' body weight changed in Canadian federal penitentiaries during incarceration based on a history of tobacco use prior to incarceration. Our aim was to gain insight on the factors related to inmate weight gain by drawing a comparison between the weight gained (from admission to follow-up) in inmates who were in withdrawal from tobacco, or other substances (drugs and/or alcohol), and inmates not battling addictions during incarceration. Because smoking cessation is known to be associated with weight gain, ${ }^{31} 32$ we hypothesised that inmates with a history of tobacco use would gain more weight during incarceration, in a penitentiary with a total tobacco ban, than inmates not in withdrawal from tobacco. We also hypothesised that inmates withdrawing from other substances (drugs and alcohol) would also gain more weight than inmates not going through withdrawal.

\section{MATERIALS AND METHODS}

This study is part of a larger research project that explored multiple determinants related to weight gain during incarceration in Canadian federal penitentiaries. Using the same methodology as described below, we also collected data on food intake ${ }^{33}$ and physical activity. ${ }^{34}$

\section{Participants}

Participants for this research project were male and female inmates who volunteered to take part in the study. To participate, they had to be incarcerated for at least 6 months in their current federal institutions in the Ontario or Atlantic region. In the Ontario region, we collected data from inmates housed in five institutions near Kingston (of the seven institutions in the Ontario region). ${ }^{15}$ These institutions were selected for geographical feasibility reasons. In the Atlantic region, we collected data from inmates housed in all five institutions in New Brunswick and Nova Scotia. ${ }^{15}$ Critically ill inmates admitted to the prison hospital and pregnant inmates were excluded from the study. The capacity of these institutions was approximately 2700 inmates.

\section{Sampling}

The sample was based on the National Statistical Service sample size calculator. There were approximately 1630 inmates eligible to participate in the study (they were in their current institution for at least 6 months and had anthropometric measurements taken on admission in their medical chart). Our sample had to be at least 300 inmates. ${ }^{35}$ The inmate population is heavily male-dominated; $\sim 95 \%$ of inmates are male, whereas only $~ 5 \%$ are female. Consequently, we attempted to recruit the most volunteers from the one female institution in Ontario and the one in the Atlantic region. The sampling was stratified to ensure an adequate number of participants from both sexes and from institutions with each feeding system to ensure the best possible comparison. We ended up recruiting far more male participants because many of them wanted to volunteer, and this increased the power of our statistical analysis. For ethical reasons, we accepted all participants who volunteered. A condition of our ethics approval was to accept all eligible volunteers to avoid feelings of rejection.

\section{Data collection}

Research assistants (trained registered dietitians) gathered data from 754 inmates who volunteered for a $30 \mathrm{~min}$ face-to-face interview from May 2016 until September 2017. They objectively measured participants' height, 
weight and waist circumference following a standardised protocol. Then they subtracted current anthropometric data from the measurements recorded in the medical charts of participants (taken at the beginning of incarceration following a similar protocol) to determine anthropometric changes during incarceration. The standardised protocol was guided by a WHO report. ${ }^{36}$ Participants' height was measured by standing against the wall, and weight measured on a scale. Two measurements were taken, and a third was taken if the first two measurements had a significant difference $(\geq 0.5 \mathrm{~cm}$ for height and $>0.5 \mathrm{~kg}$ for weight). The final recorded measurement was the mean of the two nearest values. The measured data were then used to calculate body mass index (BMI) $\left(\mathrm{kg} / \mathrm{m}^{2}\right) .{ }^{36}$ The anthropometric measurements taken on admission were taken by healthcare professional staff (registered nurses), using a professional-grade, calibrated equipment and following a standardised protocol from Correctional Service Canada.

\section{Outcomes}

The main outcome measures for this study were body weight change $(\mathrm{kg})$, BMI change $\left(\mathrm{kg} / \mathrm{m}^{2}\right)$, annual weight change $(\mathrm{kg} /$ year $)$, BMI $\left(\mathrm{kg} / \mathrm{m}^{2}\right)$ and waist circumference $(\mathrm{cm})$ at the time of the interview. The waist circumference outcome is a stand-alone indicator since it was not measured on admission, and therefore not available to make a comparison between admission and follow-up. Waist circumference was divided into two categories (high risk and low risk) based on the WHO cut-off points (men $>102 \mathrm{~cm}$ and women $>88 \mathrm{~cm}) .{ }^{37}$ BMI categories were based on the WHO classification system. ${ }^{38}$

\section{Exposure}

During the interview, we also gathered self-reported data on tobacco and substance use (drugs and alcohol) prior to incarceration. Specifically, inmates were asked the following five questions: (1) 'Incarceration forces many lifestyle changes, were you a smoker before your incarceration?' (response options: yes or no); (2) 'How many cigarettes did you smoke per day prior to your incarceration?' (response: number of cigarettes per day); (3) 'Did you have substance abuse problems before your incarceration?' (response options: yes or no); (4) 'Which substance?' (response options: alcohol or drugs or other with specification); and (5) 'How much alcohol did you consume (per day or per week) prior to your incarceration?' (response: number of drinks per day or number of drinks per week). We gathered this information to verify if our outcome measures changed significantly based on a history of tobacco use or substance (drugs and alcohol) use. We considered that ex-smokers were inmates who responded 'yes' to question 1, we considered an inmate to have substance/drug if they responded 'yes' to question 3, and we considered an inmate to have misused alcohol when they reported drinking five drinks or more on one occasion at least once per month for the past 12 months (WHO definition of a heavy drinker) or if an inmate responded 'drinking a lot' or reported being an alcoholic to question 5.

\section{Covariates}

We adjusted our findings for the following covariates: sex, age, ethnicity, region, language, feeding system and length of incarceration as they were defined by Correctional Service Canada's standard and taken from inmates' chart. For physical activity, we adjusted for the reported time (number of minutes) spent doing moderate to vigorous physical activity per day. For diet, we gathered data from food frequency questionnaires. Then we took the variables that were most strongly associated with weight change (vegetable, fruit and sweetened beverages), and created an indicator to adjust for diet.

\section{Statistical analysis}

We performed $\chi^{2}$ and non-parametric median comparison tests (Wilcoxon and Kruskal-Wallis) to detect statistically significant changes in anthropometric measurements (weight change, BMI change, yearly weight change, BMI at follow-up and waist circumference at follow-up) between inmates with and without a history of tobacco or substance use (exposure). These tests were performed because the data did not have a normal distribution (it was skewed to the right). We performed quantile regression analysis to examine whether associations were present for various quantiles (10th, 25th, 50th, 75th, 90th) of the BMI change distribution adjusted by sex, age, ethnicity, region, language, length of incarceration, substance abuse, physical activity, diet and feeding system. We opted for the conditional quantile regression mode $^{39-41}$ instead of the multivariate regression analysis on the mean because the residuals (from the multiple regression model) did not meet the model assumptions (ie, normality, linearity, homoscedasticity). We used the Statistical Analysis Software (SAS) V.9.4, and the level of statistical significance was set at $\mathrm{p}<0.05$ for all analyses.

\section{Ethics approval}

Inmates volunteered to participate and provided their consent by signing our consent form. Since most inmates hesitated to sign our forms because of low literacy and/or fear of reprisal, participants could provide verbal consent if they preferred. ${ }^{42}$ The verbal consent was obtained by the research assistants and witnessed by correctional staff. All personal data collected were coded to ensure confidentiality.

\section{Participant involvement}

The research team met with the inmate committee members to present the project and to pilot the questionnaire with them. We then got their feedback on how to adapt it to their preferences before starting our data collection. Once the exercise was completed, we drew a random list of inmates and called them to see if they wanted to participate in our study because we planned for a random sample (to reduce selection bias). However, this recruitment strategy yielded a very poor response rate 
Table 1 BMl categories for inmates on admission and follow-up $(n=754)$ in comparison with the Canadian adult population in 2015

\begin{tabular}{|c|c|c|c|c|c|}
\hline & BMI categories & $\begin{array}{l}\text { Inmates on } \\
\text { admission (\%) }\end{array}$ & $\begin{array}{l}\text { Inmates at } \\
\text { follow-up (\%) }\end{array}$ & $P$ value & Canadians (\%) \\
\hline Underweight & $<18.5$ & 1.3 & 0.1 & $<0.0001^{*}$ & 2.7 \\
\hline Overweight & 25.0-29.9 & 41.6 & 39.4 & & 34.6 \\
\hline Obesity total & $\geq 30.0$ & 24.5 & 42.4 & & 26.7 \\
\hline Obesity class II & $35.0-39.9$ & 6.4 & 10.2 & & 6.7 \\
\hline Extreme obesity & $\geq 40.0$ & 3.4 & 5.4 & & 2.8 \\
\hline
\end{tabular}

${ }^{*} \mathrm{P}$ value is the result of the $\chi^{2}$ test between the inmates' BMI categories on admission and at follow-up. A p value $<0.05$ was considered statistically significant for the comparison between admission and follow-up. The average length between admission and follow-up was $5.0 \pm 8.3$ years.

BMI, body mass index.

because inmates found it stressful to be called on (over loudspeaker) without knowing why. We then reconvened with the inmate committee members to get advice on how to increase participation; we suggested we ask for volunteers to participate instead of using a random list. The convenience sample strategy was much more successful, with participants saying they felt more informed and empowered about why they were being called on. We recruited 754 participants over a 16-month period.

\section{RESULTS}

The participation rates were $45 \% \quad(\mathrm{n}=398 / 883$ eligible inmates) for male inmates and $42 \% \quad(n=45$ participants/107 eligible inmates) for female inmates in Ontario. The participation rates were $47 \% \quad(n=274$ participants $/ 583$ eligible inmates) for male inmates and $64 \%$ ( $n=37$ participants $/ 58$ eligible inmates) for female inmates in the Atlantic region.

Table 1 presents the proportion of inmates in each BMI category on admission and follow-up (mean duration of $5.0 \pm 8.3$ years). It also shows how these proportions compare with the Canadian adult population ( $\geq 18$ years of age) using data from Statistics Canada. ${ }^{43}$ The prevalence of obesity for the general Canadian adult population was $26.7 \%$ in 2015 , similar to our inmate sample on admission to the penitentiaries $(24.5 \%)$. However, $42.4 \%$ of inmates were considered obese at follow-up. This represents a $73 \%$ increase in inmates' obesity rates between admission and follow-up. This comparison illustrates how inmates' weight increased much more compared with the general population. Moreover, the observed weight gain is deemed undesirable since it results in an increase in the prevalence of inmate with obesity during incarceration (as opposed to seeing inmates come into the institution underweight and having normal BMI as a result of the weight gain).
Table 2 presents the sociodemographic characteristics (age, region and ethnicity) associated with history of tobacco use and substance misuse (drugs and alcohol). Younger age was associated with more drug misuse. Regional differences were also observed. A higher proportion of inmates from the Atlantic region reported smoking tobacco, were heavier smokers and reported alcohol misuse compared with inmates from the Ontario region. Inmates with Aboriginal backgrounds reported higher rates of smoking and substance misuse (drugs and alcohol). Sex and language were not associated with tobacco use or substance misuse (data not shown in the table).

Table 3 shows the waist circumference and BMI data at follow-up (measured at the time of the interview) for inmates with and without a history of tobacco use and substance misuse. We did not observe a significant difference in waist circumference and BMI between inmates with or without a history of tobacco use. But we observed that the proportion of inmates with high-risk waist circumference increased in a dose-response fashion with the number of cigarettes smoked prior to incarceration. Inmates with a history of tobacco use or drug misuse were also more likely to have a high-risk waist circumference and to be obese than those without a history of tobacco use and substance misuse. In addition, there was a strong positive correlation $(r=0.82)$ between waist circumference and BMI at follow-up (data not shown).

Table 4 presents the data on median weight change, median BMI change and median annual weight change for inmates who had a history of tobacco use or substance misuse (drugs and alcohol) compared with inmates who did not. More than two-thirds $(67.5 \%)$ of our sample reported tobacco use before incarceration. We found that ex-smokers gained roughly twice the amount of weight compared with non-smokers over time $(7.5 \mathrm{~kg}$ vs $3.7 \mathrm{~kg}$, respectively). Moreover, weight gain was related to 


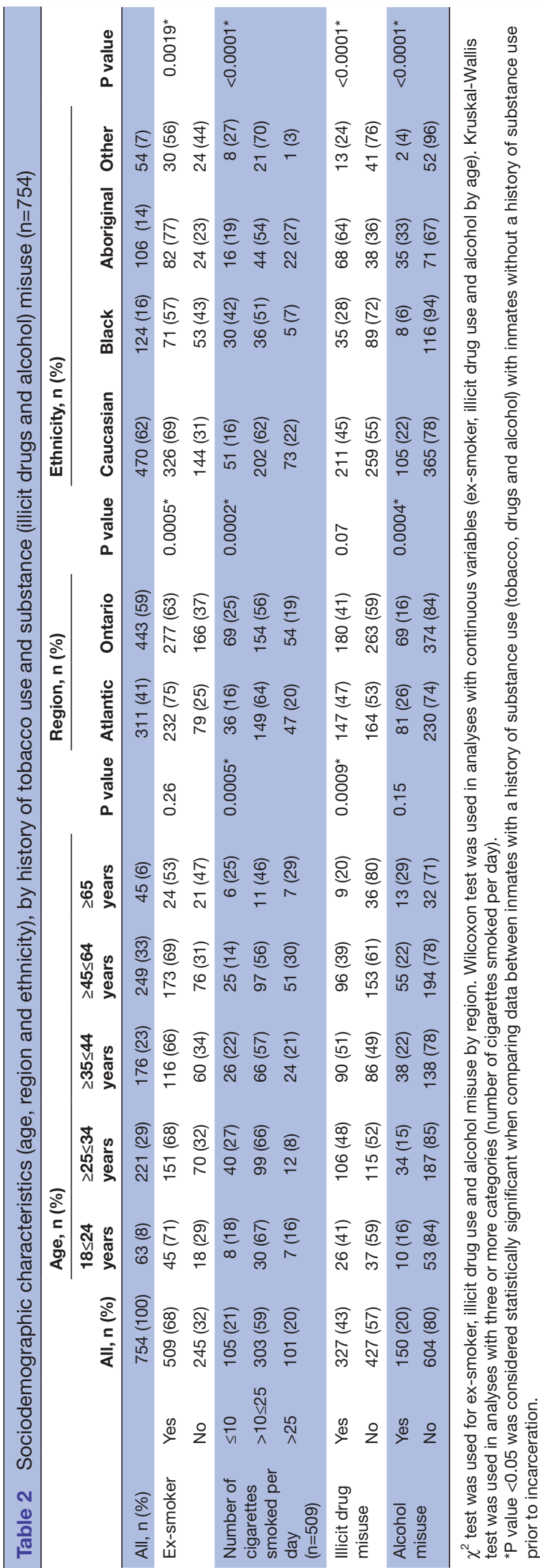

the number of cigarettes smoked daily before incarceration, with heavy smokers gaining the most (light smokers ( $\leq 10$ cigarettes/day) gained $5.6 \mathrm{~kg}$ vs $10.2 \mathrm{~kg}$ for heavy smokers ( $>25$ cigarettes/day)). Approximately $50 \%$ of inmates reported a history of substance misuse prior to incarceration. These inmates gained $64 \%$ more weight, with a median weight gain of $7.4 \mathrm{~kg}$, compared with $4.5 \mathrm{~kg}$ for inmates not battling an addiction to substances (drugs and/or alcohol) during incarceration. The type of substance was also associated with the amount of weight gained. The median weight gain for inmates with a history of drug misuse was three times higher than the weight gain of inmates with a history of alcohol misuse (8.4 kg vs $2.6 \mathrm{~kg}$, respectively). Globally, BMI change and annual weight change followed a pattern similar to weight change.

Table 5 presents the results of a quantile regression coefficients analysis that confirms the association between BMI change and a history of smoking. For inmates from the groups with the highest weight change (75th and 90th percentiles), non-smokers had, respectively, 1.64 and 2.3 lower BMI points than ex-smokers. These findings also show similar findings for alcohol misuse. Moreover, BMI gain was significantly higher for inmates below the age of 45, for inmates of Aboriginal decent and inmates who were incarcerated the longest (length of incarceration $>5$ years). These findings were adjusted for sociodemographic factors (sex, age, region, language and ethnicity) as well as for other factors (length of incarceration, physical activity, feeding system and diet). Once findings were adjusted for confounders, the weight gain by number of cigarettes disappeared, suggesting the relationship was more influenced by another factor.

\section{DISCUSSION}

The most important finding of this study is that ex-smokers who were forced to quit smoking during incarceration gained more weight, and at a faster rate, than non-smokers did $(1.6 \mathrm{~kg} /$ year and $2.4 \mathrm{BMI}$ increase for ex-smokers vs $0.9 \mathrm{~kg} /$ year and $1.2 \mathrm{BMI}$ increase for non-smokers). This represents an overall gain of roughly twice the weight than non-smokers did $(7.5 \mathrm{~kg}$ vs $3.7 \mathrm{~kg}$ for ex-smokers and non-smokers, respectively). This weight gain was deemed unhealthy since most inmates had a normal or overweight BMI on admission (33\% had normal BMI and $42 \%$ had overweight BMI), then weight gain in prison $(7.5 \mathrm{~kg}$ for ex-smokers) put a significant proportion of our sample in the obese range (BMI $\geq 30 \mathrm{~kg} / \mathrm{m}^{2}$ ). Our findings revealed that obesity rates went from $25 \%$ on admission to $42 \%$ at follow-up (or time of the study), representing a $68 \%$ increase in obesity rates. Moreover, since most ex-smokers will likely resume smoking once released from prison, ${ }^{7174}$ they may end up with two compounding risk factors for developing chronic diseases. Many inmates are already vulnerable to unhealthy weight gain by being incarcerated, ${ }^{26}$ and the added stress of involuntary tobacco cessation puts smokers at an even higher risk of becoming 
Table 3 Waist circumference and BMI at follow-up by tobacco use and substance misuse (drugs and alcohol)

\begin{tabular}{|c|c|c|c|c|c|c|c|c|c|}
\hline & & \multirow[b]{2}{*}{ All, n (\%) } & \multicolumn{2}{|c|}{ Waist circumference, n (\%) } & \multirow[b]{2}{*}{$P$ value } & \multicolumn{3}{|l|}{ BMI, n (\%) } & \multirow[b]{2}{*}{$P$ value } \\
\hline & & & $\begin{array}{l}\text { Low risk } \\
\text { (men } \leq 102 \mathrm{~cm} \\
\text { and women } \\
\leq 88 \mathrm{~cm} \text { ) }\end{array}$ & $\begin{array}{l}\text { High risk } \\
(\text { men }>102 \mathrm{~cm} \\
\text { and } \\
\text { women }>88 \mathrm{~cm} \text { ) }\end{array}$ & & $\begin{array}{l}\text { Normal } \\
(18.5- \\
\left.24.9 \mathrm{~kg} / \mathrm{m}^{2}\right)\end{array}$ & $\begin{array}{l}\text { Overweight } \\
(25.0- \\
\left.29.9 \mathrm{~kg} / \mathrm{m}^{2}\right)\end{array}$ & $\begin{array}{l}\text { Obese } \\
\left(\geq 30 \mathrm{~kg} / \mathrm{m}^{2}\right)\end{array}$ & \\
\hline \multicolumn{2}{|l|}{ All } & $754(100)$ & $364(48.3)$ & $390(51.7)$ & & $137(18.2)$ & $297(39.4)$ & $320(42.4)$ & \\
\hline Ex-smoker & Yes & $509(67.5)$ & $240(47.2)$ & $269(52.8)$ & 0.3731 & $87(17.1)$ & $193(37.9)$ & $229(45.0)$ & 0.0786 \\
\hline \multirow{2}{*}{$\begin{array}{l}\text { Number of } \\
\text { cigarettes } \\
\text { smoked per } \\
\text { day }\end{array}$} & $>10 \leq 25$ & $301(40.1)$ & $149(49.2)$ & $154(50.8)$ & & $51(16.9)$ & $117(38.9)$ & $135(44.9)$ & \\
\hline & $>25$ & $101(13.4)$ & $34(33.7)$ & $67(66.4)$ & & $14(13.9)$ & $36(35.6)$ & $51(50.5)$ & \\
\hline \multirow{2}{*}{$\begin{array}{l}\text { Illicit drug } \\
\text { misuse }\end{array}$} & Yes & $327(43.4)$ & $143(43.7)$ & $184(56.2)$ & $0.0288^{*}$ & $43(13.1)$ & $134(41.0)$ & $150(45.9)$ & $0.0150^{\star}$ \\
\hline & No & $427(56.6)$ & $221(51.8)$ & 206 (48.2) & & $94(22.0)$ & $163(38.2)$ & $170(39.8)$ & \\
\hline
\end{tabular}

Alcohol misuse is defined as participants who drank an amount of alcohol $\geq 5$ drinks on one occasion at least once a month for the past 12 months (WHO definition of a heavy drinker) or participants who responded 'drinking a lot' or being an alcoholic. Wilcoxon test was used in analyses with two categories (ex-smoker, illicit drug misuse and alcohol misuse) in comparison with inmates who reported that they did not use those substances. Kruskal-Wallis test was used in analyses with three categories (number of cigarettes smoked per day).

${ }^{*} P$ value $<0.05$ was considered statistically significant. The average length between admission and follow-up was $5.0 \pm 8.3$ years. BMI, body mass index.

obese. This is important because a high proportion of inmates were smokers $(67.5 \%$ of our sample) before incarceration, and it illustrates a need for more support for inmates withdrawing from tobacco during incarceration in Canadian penitentiaries.

Our findings are consistent with other studies on inmate addiction that found the prevalence for tobacco use and drug misuse to be three to four times higher in the inmate population (prior to incarceration) than in the general Canadian population..$^{18} 4546$ In our study, $67.5 \%$ of inmates reported a history of tobacco use, $43.4 \%$ of inmates reported illicit drug misuse, and $32.1 \%$ of inmates reported heavy alcohol use prior to incarceration, whereas in 2016, $16.9 \%$ of Canadians used tobacco, ${ }^{47}$ $13 \%$ used illicit drugs, ${ }^{48}$ and $17.9 \%$ misused alcohol or were considered 'heavy drinkers' by WHO standards (ie, more than five drinks on one occasion at least once a month for the past 12 months). ${ }^{49}$ Overall, our findings showed that most inmates suffering from addictions (ie, tobacco and/or drugs) gained more weight during incarceration. Given the higher prevalence of tobacco and substance misuse, this puts a large proportion of inmates at increased risk of becoming obese and developing obesity-related illness.

It has been hypothesised by other authors that the rapid weight gain in the beginning of incarceration may be because inmates were withdrawing from alcohol, drugs and/or tobacco. ${ }^{28} 50$ In support of this hypothesis, studies from penitentiaries where tobacco was still permitted reported a modest weight gain $(0.7-0.96 \mathrm{~kg}$ weight gain over 1-2 years). ${ }^{23} 26275152$ Contrary to Canadian data on inmate weight gain, ${ }^{25}$ these studies found that inmates were less likely to be obese than the general population, ${ }^{23} 26275152$ possibly in part because they were incarcerated in penitentiaries that still allowed smoking.

In prison, tobacco serves a range of functions, including being a surrogate currency, a means of social control, a symbol of freedom in a group with few rights and privileges, a stress reliever, and a social lubricant. ${ }^{453}$ Therefore, the importance of tobacco in the prison environment goes beyond what would be expected in the general population. These added functions of tobacco in prison should be taken into consideration when developing smoking cessation interventions. Furthermore, since before the ban tobacco and cigarettes were the main source of currency, now there are reports that inmates use junk food (chips, chocolate bars and soda drinks) as currency, to exchange services and to gamble. ${ }^{555}$ This new phenomenon may provide insight into the obesogenic effect of the tobacco ban. It may also go beyond smokers in prison, since it can potentially influence the obesogenic environment for everyone living in this environment. Now that junk food has become the new currency, it has become omnipresent in prison and therefore possibly consumed more frequently by all inmates.

The inclusion of tobacco cessation counselling and the use of cessation aids (such as nicotine replacement therapy) are deemed essential to long-term smoking cessation. ${ }^{13} 305657$ In Canadian federal penitentiaries, these aids were available for inmates to purchase at the commissary store (or 'canteen'). This means inmates are responsible for purchasing these items themselves (with their own funds). However, there are reports that inmates cannot afford these expensive cessation aids because of very low income during incarceration (daily salary $\sim \$ 6$ per day) ${ }^{58}$ This could, in part, explain why inmates gained 


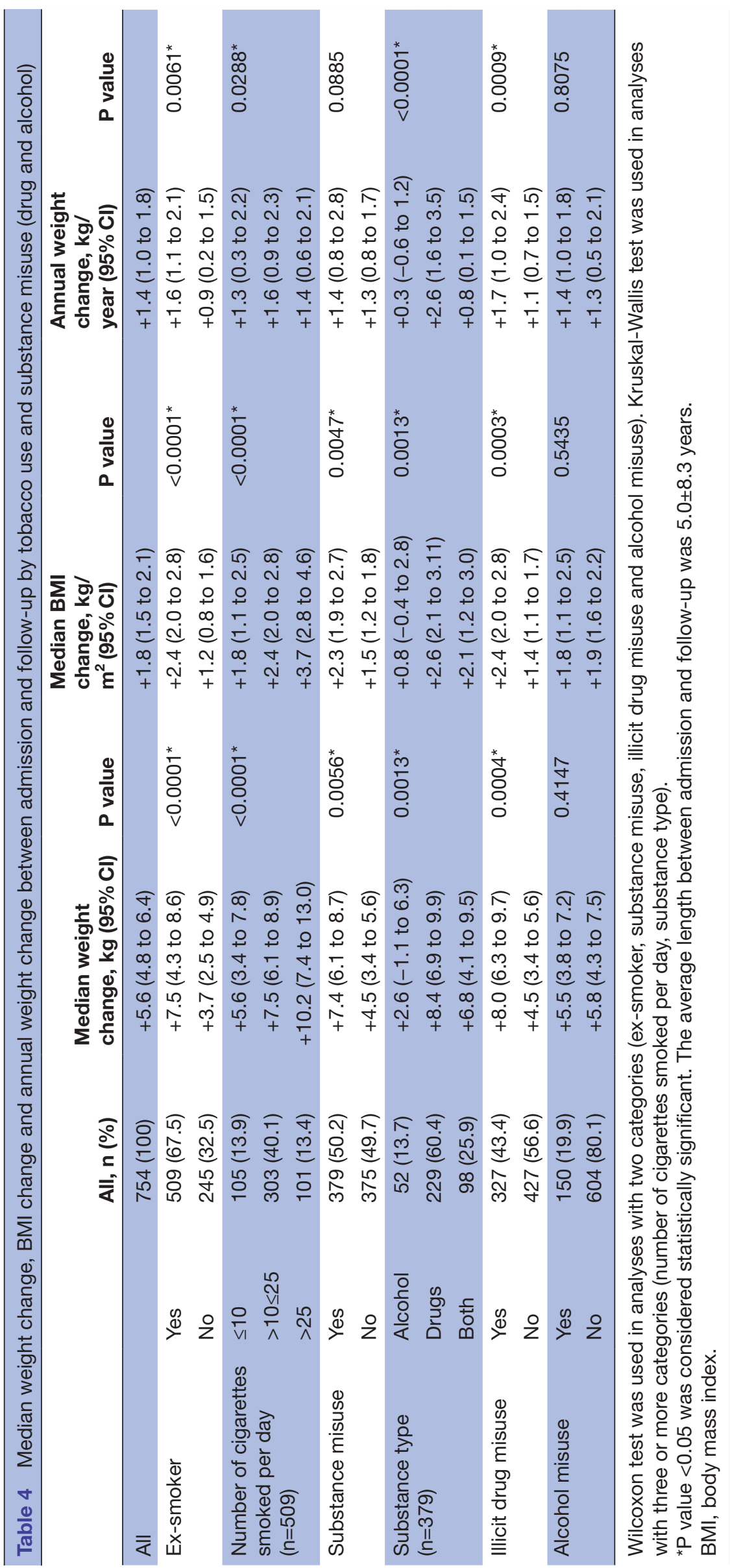




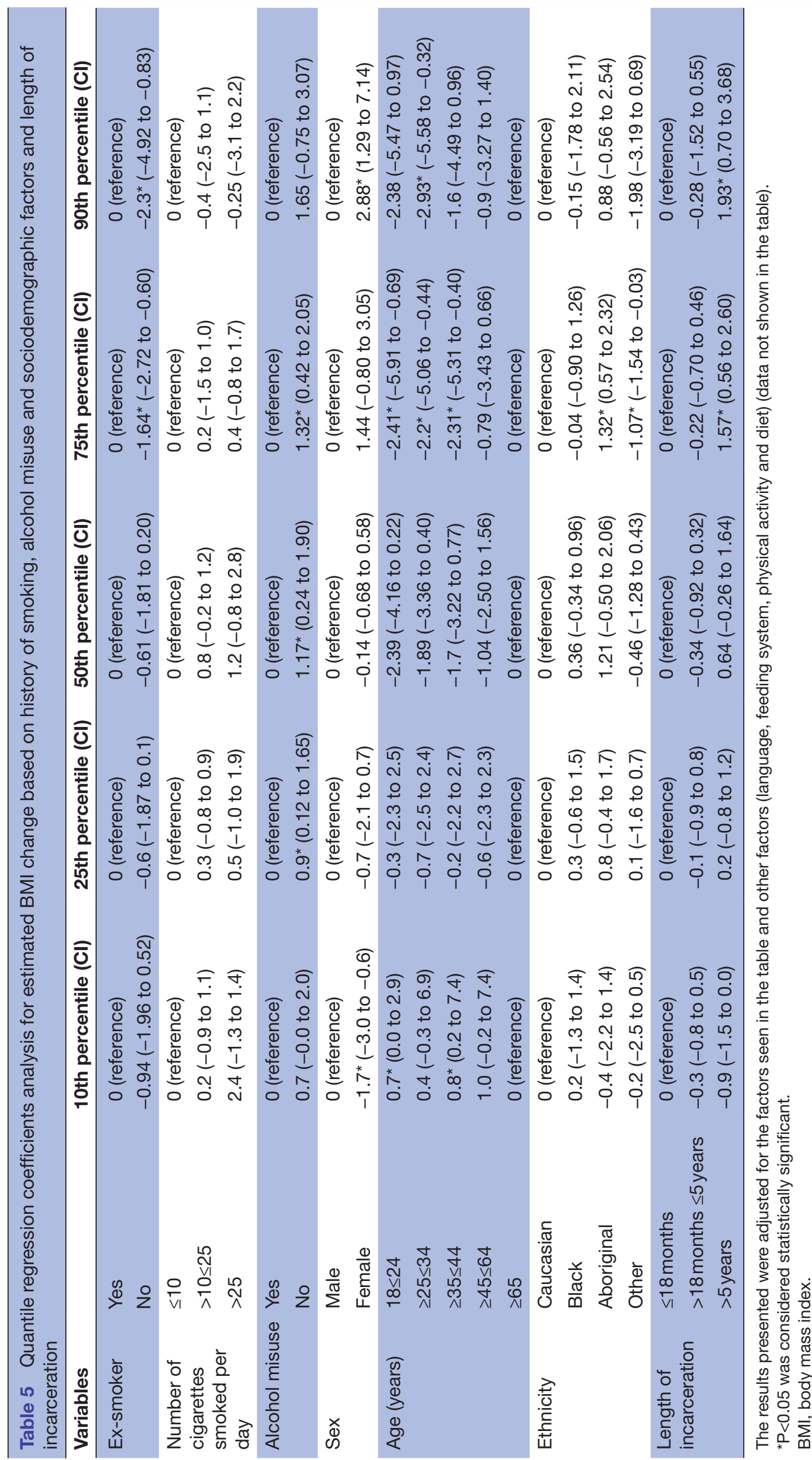


more weight when in withdrawal from tobacco during incarceration, since they have limited access to tools that may help deal with cravings. ${ }^{17}$ Furthermore, without these tools, they may turn to food to manage tobacco withdrawal symptoms. This coping strategy appears to be permanent since weight gain is sustained over time. As such, inmates who are incarcerated longer ( $>5$ years) gain significantly more weight than inmates with shorter sentences.

The tobacco ban in prison appears to be insufficient in obtaining long-term tobacco cessation. ${ }^{44}{ }^{59}$ Most studies on the subject reveal that the vast majority of inmates (up to $97 \%$ ) resume smoking within 6 months of being released back into the community. ${ }^{77}$ Consequently, once released inmates who smoke may end up with two compounding risk factors (tobacco and obesity), which put them at increased risk for health problems. The tobacco ban policy, intended to improve the prison health environment by improving air quality, ${ }^{60}$ has been successful at achieving this goal and also at reducing tobacco-related diseases. ${ }^{14}$ The risk of weight gain would unquestionably be offset by the benefits of long-term smoking cessation. ${ }^{61}{ }^{62}$ However, this may not be the case for Canadian inmates who will likely resume smoking after incarceration, since evidence indicated most inmates resume smoking once released from prison. ${ }^{7}$ In light of this reality, there are programmes aimed at offering support to inmates with continued tobacco abstinence once released from prison. For example, WISE (Working Inside for Smoking Elimination) is a programme based on motivational interviewing and behavioural therapy out of the USA that has been successful at maintaining continued tobacco cessation postrelease from institutions where tobacco is forbidden. ${ }^{1763}$ This type of programme could be helpful in Canada for inmates looking to achieve long-term smoking cessation. When planning for smoking cessation programmes for inmates, it is helpful to note that many inmates reported wanting to achieve something positive while in prison, and they say quitting smoking while in prison would be a great accomplishment. ${ }^{64}$ From this perspective, smoking cessation in prison could be viewed as a unique opportunity to help a population typically resistant to mainstream smoking cessation strategies. ${ }^{64} \mathrm{~A}$ WHO paper on tobacco bans in prison reported that inmates saw incarceration as an opportunity for smoking cessation and identified physical activity as a substitute for smoking. ${ }^{64}$ From a policy perspective, this means that including physical activity in a smoking cessation programme in prison could help inmates to quit smoking successfully and could also help with the unintended weight gain from smoking abstinence during incarceration. Moreover, physical activity could also potentially replace other above-mentioned functions related to tobacco in prison, such as acting as a stress reliever and a social lubricant.

In comparison with inmates who smoked, inmates suffering from drug withdrawal also gained more weight than inmates not going through withdrawal. They gained
$8.0 \mathrm{~kg}$ compared with inmates without a history of drug use, who gained $4.5 \mathrm{~kg}$, that is, a difference of $78 \%$ between these two groups. At follow-up, $87 \%$ of inmates with a history of illicit drug misuse were overweight or obese $\left(\right.$ BMI $\left.\geq 25 \mathrm{~kg} / \mathrm{m}^{2}\right)$. This suggests the median $8 \mathrm{~kg}$ weight gain in those inmates did not help most of them go from underweight (since only $1.3 \%$ of our sample was underweight on admission) to a normal weight, but rather from a normal weight to overweight or obese. Prison staff often share the opinion that drug users enter prison underweight and the observed weight gain is deemed healthy, but our findings did not support this opinion. However, inmates withdrawing from alcohol misuse did not gain significantly more weight than inmates without a history of alcohol misuse, whereas the weight gain seen in inmates with a history of tobacco use or drug misuse was similar during incarceration.

\section{Limitations}

This study should be interpreted in light of the following limitations. First, the observational nature of the data precludes inferences about causality. Second, the data collected on tobacco and substance (alcohol and drug) misuse (exposure) were self-reported by participants, and therefore subject to recall and social desirability biases. ${ }^{65}$ Third, residual confounding by unmeasured variables (ie, duration of tobacco use and previous quit attempts) is a possibility. Fourth, the measurements on admission were taken retrospectively from the medical charts. Consequently, these measurements were taken by healthcare staff using equipment different from ours for the study. Finally, our convenience sample may be subject to selection bias.

\section{CONCLUSION}

In conclusion, inmates are vulnerable to weight gain during incarceration in part because of withdrawal from tobacco and drugs in Canadian penitentiaries. Although the decision to ban tobacco from penitentiaries contributes to a healthier environment in prison, the ban was suspected to have unintended consequences, and our findings have identified weight gain as one of those unintended consequences. Our findings suggest that tobacco ban in prisons could partly explain the large variation in weight gain seen in certain penitentiaries. For further research, a large-scale analysis examining weight gain data from penitentiaries where tobacco is banned, compared with penitentiaries where smoking is still permitted, could confirm our suspicion. Since many inmates view incarceration as an opportunity for smoking cessation, a carefully planned intervention programme (with postrelease support) could help empower inmates to abstain from tobacco long term. A follow-up study postrelease from prison to assess weight changes and smoking status could provide information on how to help inmates manage their addictions and their weight over time. 
Acknowledgements Inmate committee members were instrumental in encouraging participants to volunteer and providing valuable feedback on our questionnaire.

Contributors CJ and LD directed data planning, data collection and data analysis for the study. J-PC provided guidance on outcomes to examine and statistical tests to perform, and revised the manuscript extensively. MD performed all statistical analyses. CJ drafted the manuscript. CR coded the data and prepared them for statistical analysis. All of the authors contributed to the conception and design of the study and the interpretation of the data, critically revised the manuscript for important intellectual content, gave final approval of the version to be published and agreed to be accountable for all aspects of the work.

Funding This study was funded by the Consortium national de formation en santé (CNFS). The funders had no involvement in study design; collection, analysis or interpretation of data; writing the manuscript; or the decision to submit the manuscript for publication.

Competing interests CJ currently works as Coordinator of the Nutrition Management Program for Correctional Service Canada. The data and their interpretation are fully represented in the paper, and no censorship has occurred.

Patient consent for publication Not required.

Ethics approval The Research Ethics Board at the University of Ottawa and the research branch at Correctional Service Canada (file number: H12-15-02).

Provenance and peer review Not commissioned; externally peer reviewed.

Data sharing statement In conducting this study we created a large database on our participants; some data were not published. It is available at the University of Ottawa.

Open access This is an open access article distributed in accordance with the Creative Commons Attribution Non Commercial (CC BY-NC 4.0) license, which permits others to distribute, remix, adapt, build upon this work non-commercially, and license their derivative works on different terms, provided the original work is properly cited, appropriate credit is given, any changes made indicated, and the use is non-commercial. See: http://creativecommons.org/licenses/by-nc/4.0/.

\section{REFERENCES}

1. Collier R. Prison smoking bans: clearing the air. Can Med Assoc J 2013;185:E474.

2. Cropsey K, Eldridge GD, Ladner T. Smoking among female prisoners: an ignored public health epidemic. Addict Behav 2004;29:425-31.

3. Voglewede JP, Noel NE. Predictors of current need to smoke in inmates of a smoke-free jail. Addict Behav 2004;29:343-8.

4. Butler T, Richmond R, Belcher J, et al. Should smoking be banned in prisons? Tob Control 2007;16:291-3.

5. Ramaswamy M, Faseru B, Cropsey KL, et al. Factors associated with smoking among adolescent males prior to incarceration and after release from jail: a longitudinal study. Subst Abuse Treat Prev Policy 2013;8:37.

6. Valera P, Cook SH, Darout R, et al. "They are not taking cigarettes from me. I'm going to smoke my cigarettes until the day I die. I don't care if I get cancer": smoking behaviors of men under community supervision in New York City. Nicotine Tob Res 2014;16:800-6.

7. Lincoln T, Tuthill RW, Roberts CA, et al. Resumption of smoking after release from a tobacco-free correctional facility. J Correct Health Care 2009;15:190-6.

8. Reid JL, Hammond D, Burkhalter R, et al. Tobacco use in canada: patterns and trends, 2012 edition. Waterloo, Ontario: Propel Center for Population Health Impact, 2012.

9. Reid JL, Hammond D, Rynard VL, et al. Tobacco use in canada: patterns and trends. Waterloo, Ontario: University of Waterloo, 2017.

10. Statistics Canada. Smokers in Canada-Canadian Health Measures survey, 2015.

11. Butler T, Andrews G, Allnutt S, et al. Mental disorders in Australian prisoners: a comparison with a community sample. Aust $N Z J$ Psychiatry 2006:40:272-6.

12. Etter JF, Ritter C, Christie DH, et al. Implementation and impact of anti-smoking interventions in three prisons in the absence of appropriate legislation. Prev Med 2012;55:475-81.

13. von Tigerstrom $B$. Tobacco control and the Law in Canada. In: Bailey TM, Caulfield T, Ries NM, eds. Public Health law and policy in Canda. second. Markham, ON: LexisNexis, 2008:247-300.

14. Binswanger IA, Carson EA, Krueger PM, et al. Prison tobacco control policies and deaths from smoking in United States prisons: population based retrospective analysis. BMJ 2014;349:g4542.
15. Correctional Service Canada. Institutional Profiles 2013 [updated 2013-02-11. http://www.csc-scc.gc.ca/institutions/index-eng.shtml.

16. Reitano J. Adult correctional statistics in Canada, 2015/2016: Statistics Canada, 2017.

17. Clarke JG, Stein LA, Martin RA, et al. Forced smoking abstinence: not enough for smoking cessation. JAMA Intern Med 2013:173:789-94.

18. Butler TG, Yap L. Smoking bans in prison: time for a breather? Med J Aust 2015;203:313.

19. Eldridge GD, Cropsey KL. Smoking bans and restrictions in U.S. prisons and jails: consequences for incarcerated women. Am J Prev Med 2009;37:S179-80.

20. Ritter C, Huynh CK, Etter JF, et al. Exposure to tobacco smoke before and after a partial smoking ban in prison: indoor air quality measures. Tob Control 2012;21:488-91.

21. Proescholdbell SK, Foley KL, Johnson J, et al. Indoor air quality in prisons before and after implementation of a smoking ban law. Tob Control 2008;17:123-7.

22. . World Health Organization (WHO), et alln: Moller L, Stover $\mathrm{H}$, Jurgens $\mathrm{R}$, Gatherer A, Nikogosian $\mathrm{H}$, ; eds. Health in Prison: A WHO Guide to the Essentials in Prison Health. Copenhagen, Denmark: World Health Organization, 2007.

23. Herbert K, Plugge E, Foster C, et al. Prevalence of risk factors for non-communicable diseases in prison populations worldwide: a systematic review. Lancet 2012;379:1975-82.

24. Choudhry K, Armstrong D, Dregan A. Systematic review into obesity and weight gain within male prisons. Obes Res Clin Pract 2018;12:327-35.

25. Johnson C, Chaput JP, Diasparra M, et al. Canadian federal penitentiaries as obesogenic environments: a retrospective cohort study. CMAJ Open 2018;6:E347-52.

26. Gebremariam MK, Nianogo RA, Arah OA. Weight gain during incarceration: systematic review and meta-analysis. Obes Rev 2018;19:98-110.

27. Gates ML, Bradford RK. The impact of incarceration on obesity: are prisoners with chronic diseases becoming overweight and obese during their confinement? J Obes 2015;2015:1-7.

28. Clarke JG, Waring ME. Overweight, obesity, and weight change among incarcerated women. J Correct Health Care 2012;18:285-92.

29. Drach LL, Maher JE, Braun MJ, et al. Substance Use, Disordered Eating, and Weight Gain: Describing the Prevention and Treatment Needs of Incarcerated Women. J Correct Health Care 2016;22:139-45.

30. Cropsey KL, McClure LA, Jackson DO, et al. The impact of quitting smoking on weight among women prisoners participating in a smoking cessation intervention. Am J Public Health 2010;100:1442-8.

31. Lyons R, Raine K, Reading J, et al. Obesity in Canada a joint report from the public health agency of Canada and the canadian institute for health information. Canada: Agence de santé publique au Canada et I'Institut canadien d'information sur la santé, 2011.

32. Courtemanche $\mathrm{C}$, Tchernis R, Ukert B. The effect of smoking on obesity: Evidence from a randomized trial. $J$ Health Econ 2018;57:31-44.

33. Johnson C, Chaput JP, Rioux F, et al. An exploration of reported food intake among inmates who gained body weight during incarceration in Canadian federal penitentiaries. PLoS One 2018;13:e0208768.

34. Johnson C, Chaput JP, Diasparra M, et al. Influence of physical activity, screen time and sleep on inmates' body weight during incarceration in Canadian federal penitentiaries: a retrospective cohort study. Can J Public Health 2019;110:198-209.

35. Australian bureau of statistics. Sample Size Calculator. $2018 \mathrm{http}: / /$ www.abs.gov.au/websitedbs/D3310114.nsf/home/Sample+Size+ Calculator.

36. WHO Expert Committee. Physical Status: The use and interpretation of anthropometry: Geneva, 1995.

37. World Health Organization (WHO). Waist circumference and waist-hip ratio: report of a WHO expert consultation. Geneva, 2008. Report No.: 9789241501491.

38. World Health Organization (WHO). Obesity and overweight- Fact sheet, 2016.

39. Cook BL, Manning WG. Measuring racial/ethnic disparities across the distribution of health care expenditures. Health Serv Res 2009;44:1603-21.

40. Lê Cook B, Manning WG. Thinking beyond the mean: a practical guide for using quantile regression methods for health services research. Shanghai Arch Psychiatry 2013;25:55-9.

41. Koenker R, Hallock KF. Quantile regression. Journal of Economic Perspectives 2001;15:143-56. 
42. Gostin LO, Vanchieri C, Pope A. Ethical considerations for research involving prisoners. Washington, DC: Institute of Medicine of the National Academies, 2007.

43. Canada S. Measured adult body mass index (BMI) (World Health Organization classification), by age group and sex, Canada and provinces-Table 105-2023. Canadian Community Health Survey, CANSIM. Nutrition 2015

44. Bock B, Lopes CE, van den Berg JJ, et al. Social support and smoking abstinence among incarcerated adults in the United States: a longitudinal study. BMC Public Health 2013;13:859-2458.

45. McVie F. Drugs in federal corrections - The issues and challenges. Ottawa: Correctional Service Canada, 2015. Contract No.: 3

46. Agozino B, Volpe SL. Health inequalities in correctional institutions: implications for health inequalities in the community. J Correct Health Care 2009;15:251-67.

47. Statistics Canada. Smoking, 2016. Health Reports, 2017.

48. Statistcs Canada. Canadian Tobacco Alcohol and Drugs (CTADS): 2015 summary: Ottawa, 2016

49. Statistics Canada. Heavy Drinkers in Canada-Canadian Health Measures Survey, 2015.

50. Cropsey KL, Kristeller JL. The effects of a prison smoking ban on smoking behavior and withdrawal symptoms. Addict Behav 2005;30:589-94.

51. Plugge EH, Foster CE, Yudkin PL, et al. Cardiovascular disease risk factors and women prisoners in the UK: the impact of imprisonment. Health Promot Int 2009;24:334-43.

52. Lagarrigue A, Ajana S, Capuron L, et al. Obesity in French inmates: gender differences and relationship with mood, eating behavior and physical activity. PLoS One 2017;12:e0170413.

53. van den Berg JJ, Bock B, Roberts MB, et al. Cigarette smoking as an expression of independence and freedom among inmates in a tobacco-free prison in the United States. Nicotine Tob Res 2014;16:238-42.

54. Turner NE, Preston DL, McAvoy S, et al. Problem gambling inside and out: the assessment of community and institutional problem gambling in the Canadian correctional system. J Gamb/ Stud 2013;29:435-51.

55. Renaud D. Crime organisé dans les pénitenciers: croustilles, boissons gazeuses et extorsion. Le nouveau commerce illicite des gangs dans les pénitenciers. La Presse 2017.

56. Lawn S, Hehir A, Indig D, et al. Evaluation of a totally smokefree forensic psychiatry in-patient facility: practice and policy implications. Aust Health Rev 2014;38:476-82.

57. de Andrade D, Kinner SA. Systematic review of health and behavioural outcomes of smoking cessation interventions in prisons. Tob Control 2016;26:495-501.

58. Correctional Service Canada. Offender Program Assignments and Inmate Payments. 2016 http://www.csc-scc.gc.ca/acts-andregulations/730-cd-eng.shtml.

59. Jin X, Kinner SA, Hopkins R, et al. Brief intervention on Smoking Nutrition, Alcohol and Physical (SNAP) inactivity for smoking relapse prevention after release from smoke-free prisons: a study protocol for a multicentre, investigator-blinded, randomised controlled trial. BMJ Open 2018;8:e021326.

60. Correctional Service Canada. Commissioner's Directive: Exposure to Second Hand Smoke Ottawa. 2014 http://www.csc-scc.gc.ca/ politiques-et-lois/259-cd-eng.shtml.

61. Rigotti NA, Clair $\mathrm{C}$. Weight gain after smoking cessation: more data to refute concerns. Eur Heart J 2018;39:1532-4.

62. Kim K, Park SM, Lee K. Weight gain after smoking cessation does not modify its protective effect on myocardial infarction and stroke: evidence from a cohort study of men. Eur Heart $J$ 2018;39:1523-31.

63. Khavjou OA, Clarke J, Hofeldt RM, et al. A captive audience: bringing the WISEWOMAN program to South Dakota prisoners. Womens Health Issues 2007;17:193-201.

64. Baybutt M, Ritter C, Stöver H. Tobacco use in prison settings: a need for policy implementation. Geneva, Switzerland: World Health Organization, 2013.

65. Porta M. A dictionary of epidemiology: Oxford University Press, 2008. 